\title{
Laboratory Test Data Collection Day
}

National Cancer Institute

\section{Source}

National Cancer Institute. Laboratory Test Data Collection Day. NCI Thesaurus. Code C83306.

The day of the week a laboratory test data was collected. 